\title{
Urinary Glycosaminoglycans in Asthmatic Children in Relation to Disease Control by Inhaled Corticosteroids
}

\section{Deraz TE ${ }^{1}$, Terez B Kamel ${ }^{1}$, Enas S Nabih ${ }^{2 *}$ and Walaa A Abdelazem ${ }^{1}$}

${ }^{1}$ Department of Pediatrics, Ain Shams University, Egypt

${ }^{2}$ Department of Medical Biochemistry and Molecular Biology, Ain Shams University, Egypt

"Corresponding author: Nabih ES, Department of Medical Biochemistry and Molecular Biology, Ain Shams University, 11381, Cairo, Egypt, Tel: +201223180464; Email: enassamer@hotmail.com

Received date: June 26, 2015; Accepted date: August 04, 2015; Published date: August 11, 2015

Copyright: (C) 2015 Deraz TE, et al. This is an open-access article distributed under the terms of the Creative Commons Attribution License, which permits unrestricted use, distribution, and reproduction in any medium, provided the original author and source are credited.

\begin{abstract}
Background: Chronic inflammation and airway remodeling are important characteristics of human asthma. Increased deposition of extracellular matrix in the airway wall contributes to airway remodeling in asthmatics. Glycosaminoglycans (GAGs) are polysaccharides attached to a protein core to form proteoglycans, a component of the ECM.

Objective and method: In this study, urinary GAGs levels of asthmatic children were investigated in relation to disease control and medication. Sixty asthmatic children (48 boys, 12 girls), aged 4-14 years, were recruited in the study; twenty were controlled asthma on inhaled fluticasone, twenty were uncontrolled asthma due to incompliance on inhaled fluticasone and twenty uncontrolled who were only on relief medications. Age and gender matched 20 healthy controls were also included. GAGs were precipitated from collected early morning urine samples, isolated and quantified then expressed in $\mu \mathrm{g}$ GAGs/mg creatinine/m2. Urinary GAGs levels were significantly lower among healthy controls than asthmatics $(58.0 \pm 31.0$ and $98.1 \pm 41.0 \mu \mathrm{g} / \mathrm{mg}$ creatinine $/ \mathrm{m} 2$ respectively) with significant higher values in children on inhaled corticosteroids (ICS) whether controlled or uncontrolled $(113.3 \pm 56.8$ and $88.9 \pm$ $49.7 \mu \mathrm{g} / \mathrm{mg}$ creatinine $/ \mathrm{m} 2$ respectively) than asthmatics on relief medications $(32.2 \pm 23.5 \mu \mathrm{g} / \mathrm{mg}$ creatinine $/ \mathrm{m} 2)$. Furthermore, we found a positive correlation between daily doses of inhaled fluticasone and urinary GAGs values.
\end{abstract}

Conclusion: Urinary GAGs secretion is reduced in asthmatic children using only relief medication but it is increased in those on long-term treatment with ICS which plays an important role in preventing remodeling.

Keywords: Airways remodeling; Bronchial asthma; ICS; Glycosaminoglycans; GAGs

\section{Introduction}

Asthma is a prevalent chronic disease which is not optimally controlled in about $50 \%$ of cases even in developed countries. It has a high burden of morbidity especially if not controlled [1]. Airway inflammation, a major element of asthma pathophysiology, and related to asthma severity [2,3] and asthma control [4] and causing systemic signs of inflammation as well [5]. Easily obtainable markers of systemic inflammation especially those related to clinical control of asthma may help in clinical decision-making. Recently, a number of studies investigated the sensitivity of circulating inflammatory markers in the evaluation of asthma control. Increase in proinflammatory cytokines, such as interleukin-6 [6] and tumor necrosis factor- $\alpha$ $[7,8]$ have already been described in asthmatic patients as well as elevated circulating C-reactive protein levels in non-allergic [9], and neutrophilic asthma [10]. In steroid-naive asthmatic patients Creactive protein levels negatively correlated with indices of lung function (forced expiratory volume in one second (FEV1), FEV1/ forced vital capacity and forced mid-expiratory flow) and positively with sputum eosinophil count [11].

Chronic inflammation and airway remodeling are important characteristics of human asthma. These include the infiltration of inflammatory cells and an abnormal accumulation of extracellular matrix (ECM) in the sub-epithelial basement membrane region and sub mucosa [12,13]. Therefore, increases in ECM degradation products may be associated with airway fibrosis, and decline in lung function [12-14]. Glycosaminoglycans (GAGs) are long straight chain polysaccharides composed of repeated disaccharide units which occur in free form or attached to a protein core to form proteoglycans. Proteoglycans are important structural and functional components of the extracellular matrix (ECM) and basement membrane [15-17].

Airway remodeling is associated with poor clinical outcomes among asthmatic patients. Early diagnosis and prevention of airway remodeling has the potential to decrease disease severity, improve control and prevent disease expression [12,15]. The relationship between structural changes and clinical and functional abnormalities clearly deserves further investigation and understanding the contribution of ECM accumulation to asthma pathogenesis may lead to new therapeutics for patients with asthma.

Therefore, we conducted this study to evaluate the impact of asthma control by long-term treatment with inhaled corticosteroids on airway remodeling compared to relief medication through the evaluation of urinary excretion of GAGs. 


\section{Methods}

\section{Study population}

Sixty asthmatic children (48 boys, 12 girls), aged 4-14 years, were randomly recruited from the Pediatric Chest Clinic, Children's Hospital, Ain Shams University. Patients were selected according to the global initiative for asthma "GINA"5. Twenty were controlled asthma on the inhaled fluticasone "ICS"+; twenty were uncontrolled asthma due to incompliance on the inhaled fluticasone "ICS"; and twenty uncontrolled who were only on relief medications "non-ICS".

"ICS ${ }^{+"}$ group were free from acute exacerbations during the three months prior to study. They were treated with low to medium doses of ICS at a constant dose for at least three months. According to GINA5, controlled asthma was taken as the need for rescue medications (shortacting $\beta 2$-agonists) twice or less a week, no limitation of day activity, no nocturnal symptoms, twice or less a week day time symptoms and FEV $1 \%>80 \%$ predicted. There was no use of systemic steroids in the previous 12 months.

While uncontrolled asthma among both "ICS" and "non-ICS" groups, was defined as having three or more features of the following: need for rescue medications more than twice a week, any limitation of day activity, any nocturnal symptoms, more than twice a week daytime symptoms and FEV $1 \%>80 \%$ predicted or had required hospitalizations for asthma in the last year [13]. Age and gender matched non-atopic, non-asthmatic healthy children $(n=20)$ were chosen as controls. They were selected from the geographic area surrounding the place of study. There was no significant difference in school grade between children participating in the study.

All patients' groups and controls were examined, underwent spirometry then urine samples were collected to determine urinary GAGs.

This study has complied with the principles laid down in the Declaration of Helsinki, adopted by the $18^{\text {th }}$ World Medical Assembly, Helsinki, Finland, June 1964, and recently amended at the $59^{\text {th }}$ World Medical Assembly, Seoul, Korea, and October 2008. The entire protocol was approved by institutional ethical committee. All parents or care givers provided signed informed consent for participation in the study as required.

\section{Spirometry}

At least $8 \mathrm{hrs}$ before the test, short-acting bronchodilators were stopped. Dynamic spirometry (Jaeger, Germany) was performed, with measurement of forced expiratory volume in $1 \mathrm{sec}$ (FEV1)\% of predicted, according to standards of both European Respirator Society and American Thoracic Academy [18]. The highest values of FEV1 of three forced expiratory maneuvers were used.

Urine samples collection and processing: Each participant was asked to void early morning urine sample in a sterile container. Each urine sample was centrifuged at $3000 \mathrm{rpm}$ for $25 \mathrm{~min}$ and the supernatant was divided into two aliquots stored at $-80^{\circ} \mathrm{C}$ until used; one without preservative used for measurement of creatinine using creatinine Biolabo kit (BIOLABO SA, Maizy, France) according to manufacturers' instructions and the second aliquot was preserved by the immediate addition of methanol $(0.1 \mathrm{ml}$ methanol $/ 10 \mathrm{ml}$ urine $)$ used for measurement of glycosaminoglycans.
Quantitative determination of urinary glycosaminoglycans: Urinary glycosaminoglycans "GAGs " were precipitated according to the method of Di Ferrante [19] and adapted by Pennock [20]. Twenty five milliliters of each preserved sample was centrifuged at $3000 \mathrm{rpm}$ for 25 $\min$ and $5 \mathrm{ml}$ of supernatant was precipitated with $10 \%$ cetylpyridinium chloride purchased from Sigma-Aldrich Chemie $\mathrm{GmbH}$, Steinheim, Germany. The precipitate was collected by centrifugation, washed twice with 95\% ethanol containing 10\% potassium acetate and dissolved in $1 \mathrm{ml}$ of $0.05 \mathrm{M} \mathrm{NaOH}$. Glycosaminoglycans were determined in urine according to the previously described method of Whitley et al. [21], using chondroitin sulfate sodium salt (from shark cartilage, no. immunoassay C4384) purchased from Sigma-Aldrich Chemie $\mathrm{GmbH}$, Steinheim, Germany as a standard. Briefly, a $10 \mathrm{X}$ stock solution $(0.35 \mathrm{mmol} / \mathrm{L})$ of $1,9-$ dimethylmethylene blue (DMB) dye (Sigma-Aldrich Chemie GmbH, Steinheim, Germany) was made by dissolving $122 \mathrm{mg}$ of dye in $10 \mathrm{ml}$ of $95 \%$ ethanol which was then diluted to1 liter with sodium formate buffer ( $\mathrm{pH} 3.5,0.2 \mathrm{mmol} / \mathrm{L}$ ). $40 \mu \mathrm{l}$ of each urine sample (or standard) was mixed with $1.0 \mathrm{ml}$ of freshly prepared working DMB dye (1X). The absorbance was measured after 30 min incubation at $535 \mathrm{~nm}$ against buffer. The measured values were corrected for reagent blank and sample blank absorbances. Glycosaminoglycans concentrations $(\mu \mathrm{g} / \mathrm{ml})$ were determined from the standard curve and normalized to urinary creatinine then to body surface area and the results were expressed in $\mu \mathrm{g}$ GAGs $/ \mathrm{mg}$ creatinine $/ \mathrm{m}^{2}$.

\section{Statistical analysis}

Collected data were reviewed, coded, entered personal computer then analyzed statistically by SPSS software version 15 (SPSS Inc., Chicago, IL, USA). Obtained data were presented as count and percentage for categorical variables. Data are presented as mean \pm SD. The Mann Whitney-U test was used to analyze differences between two groups. Comparison of three groups was performed using analysis of variance (ANOVA) and Fisher's protected least significant difference test or Chi-squared test. Kruskal-Wallis $(\chi 2)$ test was used for comparison of more than two groups in non-parametric variables.Correlations between data were analyzed using Spearman's rank correlation test. Statistical significance was set at a value of $\mathrm{p}<0.05$.

\section{Results}

\begin{tabular}{|c|c|c|c|c|c|}
\hline & \multicolumn{2}{|l|}{ Asthma } & \multirow[b]{2}{*}{ Non-ICS } & \multirow[t]{2}{*}{ Control } & \multirow[t]{2}{*}{$\mathbf{p}$} \\
\hline & $\mathrm{ICS}^{+}$ & ICS- $^{-}$ & & & \\
\hline Subjects, $\mathrm{n}^{\neq}$ & 20 & 20 & 20 & 20 & 1 \\
\hline $\begin{array}{l}\text { Age in years, } \\
\text { Mean } \pm \mathrm{SD}^{\ddagger}\end{array}$ & $6.77 \pm 3.48$ & $8.62 \pm 2.99$ & $\begin{array}{ll}8.55 & \pm \\
2.96 & \end{array}$ & $8.62 \pm 2.46$ & 0.108 \\
\hline $\begin{array}{l}\text { Gender } \\
\text { female })^{\ddagger}\end{array}$ & $17 / 3$ & $15 / 5$ & $16 / 4$ & 8-Dec & 0.294 \\
\hline $\begin{array}{l}\text { Passive } \\
\text { smoking }^{\ddagger}, \mathrm{n}(\%)\end{array}$ & $10(50 \%)$ & $10(50 \%)$ & $8(40 \%)$ & $6(30 \%)$ & 0.283 \\
\hline $\begin{array}{l}\text { Dose of I.C.S } \\
(\mu g / d a y) ; \text { Mean } \\
\pm \mathrm{SD}^{*}\end{array}$ & $350 \pm 125$ & $750 \pm 100$ & 0 & 0 & $<0.001$ \\
\hline $\begin{array}{l}\text { Positive history } \\
\text { for atopy*, n (\%) }\end{array}$ & $14(70 \%)$ & $14(70 \%)$ & $9(45 \%)$ & $0.0(0.0 \%)$ & $<0.001$ \\
\hline
\end{tabular}




\begin{tabular}{|l|l|l|l|l|l|}
\hline $\begin{array}{l}\text { FEV1\% pred., } \\
\text { Mean } \pm \text { SD }^{*}\end{array}$ & $94.50 \pm 11$ & $73 \pm 5.0$ & $83 \pm 7.0$ & $94 \pm 9.0$ & $<0.001$ \\
\hline $\begin{array}{l}\text { FEV1/FVC, } \\
\text { Mean } \pm \text { SD }\end{array}$ & $86.5 \pm 12$ & $71 \pm 5.0$ & $74 \pm 6.0$ & $88 \pm 18$ & $<0.001$ \\
\hline $\begin{array}{l}\text { FEF 25-75\%\% } \\
\text { pred., Mean } \pm \\
\text { SD }\end{array}$ & $69 \pm 23$ & $55 \pm 27$ & $58 \pm 27$ & $100 \pm 20$ & $<0.001$ \\
\hline $\begin{array}{l}\text { Urinary GAGs } \\
(\mu g / m g \\
\text { creatinine/m²), } \\
\text { Mean } \pm \text { SD }^{*}\end{array}$ & $\begin{array}{l}113.3 \quad \pm \\
56.8\end{array}$ & $88.9 \pm 49.7$ & $\begin{array}{l}32.2 \\
23.5\end{array} \quad \pm$ & $58.0 \pm 31.0$ & $<0.001$ \\
\hline
\end{tabular}

Table 1: Demographic and Clinical Data of Asthmatic Patients and Control Groups.

ICS: inhaled corticosteroid [Fluticasone]; FEV1: forced expiratory volume in one second; FVC: forced vital capacity; FEF 25-75\%: forced mid-expiratory flow; $\%$ pred: percentage of the predicted value for age and sex. ${ }^{\ddagger} \mathrm{p}>0.05$ (non-significant), ${ }^{*} \mathrm{p}<0.05$ is significant.

Characteristics of asthmatic patients' groups and healthy control group are shown in Table 1. Age, sex distribution and positive history for passive smoking did not differ among the three studied groups $(p>0.05)$. Distribution of atopy did not differ between both groups of asthmatics $(p>0.05)$. However, asthmatic children were significantly exposed to passive smoking in comparison to healthy controls $(\mathrm{p}<0.05)$. Most studied children belonged to an urban residence near to our center (Cairo, Egypt), so residence could not be attributed as a predisposing factor for asthma in the current study. FEV1\%, FEF25-75\% of predicted for age and gender, and FEV1/FVC were lower with statistical significance among uncontrolled asthmatics when compared to $\mathrm{ICS}^{+}$responsive controlled asthmatics and healthy controls $(\mathrm{p}<0.05)$.

\begin{tabular}{|c|c|c|c|c|c|c|c|c|}
\hline \multirow{2}{*}{$\begin{array}{l}\text { Correlation } \\
\text { s }\end{array}$} & \multicolumn{2}{|c|}{$\mathrm{ICS}^{+}$group } & \multicolumn{2}{|c|}{$\mathrm{ICS}^{-}$group } & \multicolumn{2}{|c|}{$\begin{array}{l}\text { Non-ICS } \\
\text { group }\end{array}$} & \multicolumn{2}{|c|}{$\begin{array}{l}\text { Healthy } \\
\text { controls }\end{array}$} \\
\hline & $r$ & p & $r$ & p & $r$ & p & $r$ & p \\
\hline Age in years & $\begin{array}{l}-0.46 \\
5\end{array}$ & 0.039 & $\begin{array}{l}-0.60 \\
6\end{array}$ & $0.005^{*}$ & -0.445 & 0.049 & -0.571 & 0.043 \\
\hline FEV1\% Pred & 0.47 & ${ }_{*}^{0.009}$ & 0.361 & $0.048^{*}$ & 0.386 & 0.036 & 0.466 & 0.007 \\
\hline $\begin{array}{l}\text { FEF } 25-75 \% \\
\text { pred }\end{array}$ & 0.42 & ${ }_{*}^{0.020}$ & 0.391 & $0.049^{*}$ & 0.473 & 0.040 & 0.518 & 0.001 \\
\hline $\begin{array}{l}\text { Daily Dose } \\
\text { of ICS }\end{array}$ & 0.456 & 0.037 & 0.324 & $0.045^{*}$ & --- & --- & $\ldots \ldots$ & $\ldots \ldots$ \\
\hline
\end{tabular}

Table 2: Significant Correlations between Urinary GAGs and Other Studied Parameters among Asthmatic Groups and healthy controls.

${ }^{*} \mathrm{p}<0.05$ is significant. $\mathrm{r}$ : Spearman's correlation coefficient. ICS: Inhaled Corticosteroid [Fluticasone]; FEV1: Forced Expiratory Volume in one second; FVC: Forced Vital Capacity; FEF25-75\%: Forced Mid-expiratory Flow; \% pred: percentage of the predicted value for age and gender.

Urinary GAGs levels were significantly lower among healthy controls than asthmatics $(58.0 \pm 31.0$ and $98.1 \pm 41.0 \mu \mathrm{g} / \mathrm{mg}$ creatinine $/ \mathrm{m}^{2}$ respectively). Significant higher values were found in children on ICS whether controlled "ICS ${ }^{+"}$ group or uncontrolled
"ICS" ${ }^{-1}$ group $\left(113.3 \pm 56.8\right.$ and $88.9 \pm 49.7 \mu \mathrm{g} / \mathrm{mg}$ creatinine $/ \mathrm{m}^{2}$ respectively) than asthmatics on relief medications $(32.2 \pm 23.5 \mu \mathrm{g} / \mathrm{mg}$ creatinine $/ \mathrm{m}^{2}$ ). There were positive correlations between urinary GAGs values and FEV1\%, FEF25-75\% of predicted for age and gender, in addition to daily doses of inhaled fluticasone. Whilst, age was negatively correlated with urinary GAGs (Table 2).

\section{Discussion}

As inhaled corticosteroids (ICS) are considered the corner stone of chronic asthma management as they reduce symptoms and frequency of asthma exacerbation and improve lung function current study was designed to evaluate the urinary glycosaminoglycans (GAGs) as an objective marker for response to anti-inflammatory treatment of asthmatic children on inhaled corticosteroids (ICS) and reflect degree of disease control in addition to airways remodeling. The results of this study demonstrated a significant association between asthma control by long-term treatment with inhaled corticosteroids and airway remodeling among Egyptian children. It was noticed that children on inhaled corticosteroids, specifically controlled children, had a significantly higher urinary excretion of GAGs than asthmatics on relief medications and healthy controls. Thus, these findings represent another evidence for the role of corticosteroids in preventing airway remodeling.

Structural and cellular changes within the airway wall in asthma, notably increased airway smooth muscle (ASM) mass [22], vascular remodeling [23], thickening of the reticular basement membrane $(\mathrm{RBM})$, and fibroblast numbers in the lamina propria [24], have been shown to correlate with airflow limitation. Furthermore, cellular infiltration of the airway wall in asthma is related to decline in lung function [25].The increase of the ECM deposition in the airway wall contributes to the airway remodeling in asthmatics [26]. Proteoglycans are important structural and functional components of ECM, pericellular and basement membranes [27]. Proteoglycans influence cell adhesion, migration and proliferation, properties which largely depend on the nature of GAGs side chain [28]. Moreover; GAGs are involved in inflammatory mechanisms of asthma by interacting with cytokines [29-31]. Endo-bronchial biopsies obtained from patients with mild asthma showed that proteoglycans deposition was significantly increased in ECM as compared with that of healthy controls [32].

There was higher urinary GAGs mean values in asthmatic children when compared to normal children, that comes in agreement with Shute et al. [33,34] who concluded that the degradation of matrix proteoglycans and that increased levels of GAGs in the urine occurs following an episode of acute severe asthma.

In consideration to the fact that ICS is the corner stone in treating asthma and preventing airway remodeling, current study showed that urinary GAGs mean values were highest in $\mathrm{ICS}^{+}$controlled group $\left(113.3 \mu \mathrm{g} / \mathrm{mg}\right.$ creatinine $\left./ \mathrm{m}^{2}\right)$ followed by ICS-uncontrolled group (88.9 $\mu \mathrm{g} / \mathrm{mg}$ creatinine $\left./ \mathrm{m}^{2}\right)$ then non- ICS group $(32.2 \mu \mathrm{g} / \mathrm{mg}$ creatinine/ $\mathrm{m}^{2}$ ). Similarly, Priftis et al. [17] reported that urinary GAGs levels were increased in asthmatic children on ICS more than normal children and that levels of GAGs decreased in non ICS group compared to normal children. They also found that long term antiasthmatic treatment with ICS is accompanied by decreased proteoglycans deposition on the basement membrane of asthmatic children and therefore by increased GAGs secretion in the urine. Similarly, Vanacker [35] reported that allergen-induced structural 
alterations could not be reversed by treatment with inhaled corticosteroids (fluticasone propionate), but concomitant treatment could partly prevent these changes and this was accompanied by an improved airway responsiveness. Also, they concluded that treatment with steroids inhibits the structural airway changes induced by repeated allergen exposure. Furthermore, de Kluijver J [36] found that inhaled steroid treatment decreases mucosal inflammatory cells, alters proteoglycans density and prevent changes in the ECM in the bronchial wall.

This supports the hypothesis that early intervention with ICS could prevent airway remodeling in asthma. However, symptoms of uncontrolled asthma should be revised for compliance or pseudocompliance with revision of other causes of poor control e.g. comorbidity (e.g. rhinitis), ongoing exposure to triggers (e.g. pets, mite etc.), misdiagnosis, inadequate treatment, ineffective delivery of treatment (e.g. poor inhaler technique),limited treatment effectiveness (e.g. smoking interfering with steroid actions), low patient and physician expectations, low adherence with agreed asthma therapy, functional and psychological problems affecting willingness to use therapy and/or not attending medical consultation [37].

Current study also showed that there was a highly statistical significant reduction in urinary GAGs secretion in non-ICS asthmatic group compared to normal children $(32.2$ and $58.0 \mu \mathrm{g} / \mathrm{mg}$ creatinine $/ \mathrm{m}^{2}$ respectively) Shute [38] explained that by fibroblast growth factor -2 (FGF2) in asthmatic subjects that co-localizes heparin sulphate proteoglycans in epithelial and endothelial basement membranes thus contributes to tissue remodeling by increase epithelial expression and release of FGF-2 from heparin sulphate binding sites in bronchial tissue. Consequently, decreased urinary GAGs could be associated to the marked deposition of proteoglycans in the airway wall. Whilst, Engstrom et al. [39] attributed that to, limited physical activity of asthmatics as a protective mechanism of exercise induced asthma.

Urinary GAGs correlated positively to FEV1\%, FEF25-75\% of predicted for age and sex, in addition to daily doses of inhaled fluticasone; thus urinary GAGs could be considered as a non-invasive effortless marker of disease control and an indirect marker for airway remodeling and inflammation. Urinary GAGs correlates negatively with age since airway mechanics change with growth and development, thus functional consequences of remodeling will be age dependent [40].

A limitation of our study is that no specific GAGs28.31 measurements were made; however, our observations should be considered as a tiny step toward identifying an alternative objective marker of the activity of the remodeling process in childhood asthma as well as the role of ICS on such activity. So measurement of urinary GAGs prior to initiating treatment with ICS or before stepping down would have been worthy.

In conclusion, our data demonstrated that urinary GAGs secretion is reduced in children receiving usual relief medication while it is increased in asthmatics on long-term treatment with ICS. A dose dependent effect of ICS was noticed. Researchers are needed to clarify the possible role of urinary GAGs as a marker of the effectiveness of the anti-asthmatic treatment.

\section{References}

1. Rabe KF, Adachi M, Lai CK, Soriano JB, Vermeire PA, et al. (2004) Worldwide severity and control of asthma in children and adults: the global asthma insights and reality surveys. J Allergy Clin Immunol 114: 40-47.

2. Louis R, Lau LC, Bron AO, Roldaan AC, Radermecker M, et al. (2000) The relationship between airways inflammation and asthma severity. Am J Respir Crit Care Med 161: 9-16.

3. Sont JK, Han J, van Krieken JM, Evertse CE, Hooijer R, et al. (1996) Relationship between the inflammatory infiltrate in bronchial biopsy specimens and clinical severity of asthma in patients treated with inhaled steroids. Thorax 51: 496-502.

4. Volbeda F, Broekema M, Lodewijk ME, Hylkema MN, Reddel HK, et al. (2013) Clinical control of asthma associates with measures of airway inflammation. Thorax 68: 19-24.

5. Global Initiative for Asthma (2009) Global strategy for asthma management and prevention: NHLBI/WHO Report 02-3659.

6. Yokoyama A, Kohno N, Fujino S, Hamada H, Inoue Y, et al. (1995) Circulating interleukin-6 levels in patients with bronchial asthma. Am J Respir Crit Care Med 151: 1354-1358.

7. Silvestri M, Bontempelli M, Giacomelli M, Malerba M, Rossi GA, et al. (2006) High serum levels of tumour necrosis factor-alpha and interleukin-8 in severe asthma: markers of systemic inflammation? Clin Exp Allergy 36: 1373-1381.

8. Mukhopadhyay S, Hoidal JR, Mukherjee TK (2006) Role of TNFalpha in pulmonary pathophysiology. Respir Res 7: 125.

9. Olafsdottir IS, Gislason T, Thjodleifsson B, Olafsson I, Gislason D, et al. (2005) C reactive protein levels are increased in non-allergic but not allergic asthma: a multicentre epidemiological study. Thorax 60: 451-454.

10. Wood LG, Baines KJ, Fu J, Scott HA, Gibson PG (2012) The neutrophilic inflammatory phenotype is associated with systemic inflammation in asthma. Chest 142: 86-93.

11. Deraz TE, Kamel TB, El-Kerdany TA, El-Ghazoly HM (2012) Highsensitivity $\mathrm{C}$ reactive protein as a biomarker for grading of childhood asthma in relation to clinical classification, induced sputum cellularity, and spirometry. Pediatr Pulmonol 47: 220-225.

12. Jeffery PK (2001) Remodeling in asthma and chronic obstructive lung disease. Am J Respir Crit Care Med 164: S28-38.

13. Elias JA, Zhu Z, Chupp G, Homer RJ (1999) Airway remodeling in asthma. J Clin Invest 104: 1001-1006.

14. Beckett PA, Howarth PH (2003) Pharmacotherapy and airway remodelling in asthma? Thorax 58: 163-174.

15. Westergren-Thorsson G, Chakir J, Lafreniere-Allard MJ, Boulet LP, Tremblay GM (2002) Correlation between airway responsiveness and proteoglycan production by bronchial fibroblasts from normal and asthmatic subjects. Int J Biochem Cell Biol 34: 1256-1267.

16. Hocking DC (2002) Fibronectin matrix deposition and cell contractility: implications for airway remodeling in asthma. Chest 122: 275S-278S.

17. Priftis KN, Loukopoulou S, Magkou C, Sitaras NM (2006) Increased glycosaminoglycans in the urine of asthmatic children on inhaled corticosteroids. Pediatr Allergy Immunol 17: 194-198.

18. Miller MR, Crapo R, Hankinson J, Brusasco V, Burgos F, et al. (2005) General considerations for lung function testing. Eur Respir J 26: 153-161.

19. Di Ferrante NM (1967) The measurement of urinary mucopolysaccharides. Anal Biochem 21: 98-106.

20. Pennock CA (1976) A review and selection of simple laboratory methods used for the study of glycosaminoglycan excretion and the diagnosis of the mucopolysaccharidoses. J Clin Pathol 29: 111-123.

21. Whitley CB, Ridnour MD, Draper KA, Dutton CM, Neglia JP (1989) Diagnostic test for mucopolysaccharidosis. I. Direct method for quantifying excessive urinary glycosaminoglycan excretion. Clin Chem 35: 374-379.

22. Pepe C, Foley S, Shannon J, Lemiere C, Olivenstein R, et al. (2005) Differences in airway remodeling between subjects with severe and moderate asthma. J Allergy Clin Immunol 116: 544-549. 
Citation: Deraz TE, Kamel TB, Nabih ES, Abdelazem WA (2015) Urinary Glycosaminoglycans in Asthmatic Children in Relation to Disease Control by Inhaled Corticosteroids. J Allergy Ther 6: 217. doi:10.4172/2155-6121.1000217

Page 5 of 5

23. Siddiqui S, Sutcliffe A, Shikotra A, Woodman L, Doe C, et al. (2007) Vascular remodeling is a feature of asthma and nonasthmatic eosinophilic bronchitis. J Allergy Clin Immunol 120: 813-819.

24. Benayoun L, Druilhe A, Dombret MC, Aubier M, Pretolani M (2003) Airway structural alterations selectively associated with severe asthma. Am J Respir Crit Care Med 167: 1360-1368.

25. van Rensen EL, Sont JK, Evertse CE, Willems LN, Mauad T, et al. (2005) Bronchial CD8 cell infiltrate and lung function decline in asthma. Am J Respir Crit Care Med 172: 837-841.

26. Vignola AM, Mirabella F, Costanzo G, Di Giorgi R, Gjomarkaj M, et al. (2003) Airway remodeling in asthma. Chest 123: 417S-22S

27. Paulsson M (1992) Basement membrane proteins: structure, assembly, and cellular interactions. Crit Rev Biochem Mol Biol 27: 93-127.

28. Hardingham TE, Fosang AJ (1992) Proteoglycans: many forms and many functions. FASEB J 6: 861-870.

29. Culley FJ, Fadlon EJ, Kirchem A, Williams TJ, Jose PJ, et al. (2003) Proteoglycans are potent modulators of the biological responses of eosinophils to chemokines. Eur J Immunol 33: 1302-1310.

30. Singer CA, Salinthone S, Baker KJ, Gerthoffer WT (2004) Synthesis of immune modulators by smooth muscles. Bioessays 26: 646-655.

31. Wilkinson TS, Potter-Perigo S, Tsoi C, Altman LC, Wight TN (2004) Pro- and anti-inflammatory factors cooperate to control hyaluronan synthesis in lung fibroblasts. Am J Respir Cell Mol Biol 31: 92-99.

32. Huang J, Olivenstein R, Taha R, Hamid Q, Ludwig M (1999) Enhanced proteoglycan deposition in the airway wall of atopic asthmatics. Am J Respir Crit Care Med 160: 725-729.
33. Merkus PJ, van Pelt W, van Houwelingen JC, van Essen-Zandvliet LE, Duiverman EJ, et al. (2004) Inhaled corticosteroids and growth of airway function in asthmatic children. Eur Respir J 23: 861-868.

34. Shute JK, Parmar J, Holgate ST, Howarth PH (1997) Urinary glycosaminoglycan levels are increased in acute severe asthma-a role for eosinophil-derived gelatinase B? Int Arch Allergy Immunol 113: 366-367.

35. Vanacker NJ, Palmans E, Kips JC, Pauwels RA (2001) Fluticasone inhibits but does not reverse allergen-induced structural airway changes. Am J Respir Crit Care Med 163: 674-679.

36. de Kluijver J, Schrumpf JA, Evertse CE, Sont JK, Roughley PJ, et al. (2005) Bronchial matrix and inflammation respond to inhaled steroids despite ongoing allergen exposure in asthma. Clin Exp Allergy 35: 1361-1369.

37. Gustafsson PM, Watson L, Davis KJ, Rabe KF (2006) Poor asthma control in children: evidence from epidemiological surveys and implications for clinical practice. Int J Clin Pract 60: 321-334.

38. Shute JK, Solic N, Shimizu J, McConnell W, Redington AE, et al. (2004) Epithelial expression and release of FGF-2 from heparin sulphate binding sites in bronchial tissue in asthma. Thorax 59: 557-562.

39. Engström-Laurent A, Hällgren R (1987) Circulating hyaluronic acid levels vary with physical activity in healthy subjects and in rheumatoid arthritis patients. Relationship to synovitis mass and morning stiffness. Arthritis Rheum 30: 1333-1338.

40. Tiddens H, Silverman M, Bush A (2000) The role of inflammation in airway disease: remodeling. Am J Respir Crit Care Med 162: S7-7S10. 